\title{
Outcomes of Open Side to End Antegrade Colorectal Single Stapler Anastomosis Versus Open End to End Retrograde Trans-anal Colorectal Single Stapler Anastomosis in Non-emergent Sigmoid and Rectal Cancers. Randomized Controlled Clinical Trial
}

Tamer.A A.M. Habeeb ( $\square$ tameralnaimy@hotmail.com )

Zagazig University

Gamal Osman

Zagazig University

Amr Ibrahim

Zagazig University

Abd-Elrahman M. Metwalli

Zagazig University

Mohamed Ibrahim Mansour

Zagazig University

Ahmed Shafik Mohamed

Zagazig University

Said Mohamed Negm

Zagazig University

Tamer Wasefy

Zagazig University

Muhammad Ali Baghdadi

Zagazig University

Bassem Sieda

Zagazig University

Ashraf Abdelmonem Elsayed

Zagazig University

Mohamed Farouk Amin

Zagazig University

Wael M Abdalla

Zagazig University

Mostafa. M. Elaidy

Zagazig University 


\section{Walid A. Mawla}

Zagazig University

Hatem Mohammad

Zagazig University

Fady Mehaney Habib

Zagazig University

Mohamed. I. Abdelhamid

Zagazig University

\section{Research Article}

Keywords: Stapler, Colo-rectal anastomosis - rectal cancer-leakage, quality of life.

Posted Date: June 7th, 2021

DOI: https://doi.org/10.21203/rs.3.rs-558926/v1

License: (c) (1) This work is licensed under a Creative Commons Attribution 4.0 International License.

Read Full License 


\section{Abstract}

Introduction: Cancer rectum and sigmoid is increasing nowadays. Resection is done by open and laparoscopic approaches. Laparoscopic approach is not available in many sites worldwide.

Aim of this study: To analyze the outcomes of open side to end (antegrade) colorectal single stapling anastomosis versus open end to end (retrograde) Trans-anal colorectal stapling anastomosis in nonemergent sigmoid and rectal cancers open surgery in adults.

Patients and Methods: Randomized controlled trial was performed on patients with sigmoid and rectal cancers between September 2016 and September 2018.

Results: The majority of studied group were between $50-70$ years with mean of $62.58 \pm 12.3$ years and $61.03 \pm 13.98$ years in group A and group B respectively. Intraoperative data showed no significant difference was founded between studied group except at operative time and mean anastomotic time as group A was significantly shorter. Univariate analysis showed that perioperative blood loss, length of stay, reoperation, inpatient death, infection and bleeding were significantly associated with leakage.

Multivariate analysis of anastomotic leak showed that infection is the only independent predictors for anastomotic leak. There is statistically significant change as regard range of bowel frequency in end to end group only $(p=0.04)$ and there is statistically significant difference as regard incontinence for Flatus in side to end group only $(p=0.00)$.There is statistically significant change in both group regard Incontinence for liquid stools $(p=0.00)$ and Clustering of stool $(p=0.00$ and $p=0.043)$. The quality of life in Antegrade group significantly drop at 6 months and return to baseline after that as regard PWB, FWB and CCS with no difference as regard SWB \& EWB while in retrograde group, the same change happened only as regard PWB \& FWB but SWB and CCS percentage didn't return to baseline

Conclusion: The side-to-end anastomoses approach is a safe approach of anastomosis and may be used as alternative to retrograde approach.

\section{Introduction}

Cancer colon and rectum prevalence comes next to bronchogenic and prostatic malignant neoplasms in male, but it is the second cancer in female following cancer breast. [1] despite the fact that 1,000,000 patients notably every year and mortality by thousands, yet patients that live from this cancer is surging in the last years due to both sumptuous appliance of investigation and novel intervention techniques. Over two thirds of colorectal cancer patients survived 5 years. [2-3].

Colorectal surgery principles target to merge the fulfillment of well-balanced free margin resection with bowel, urinary and potency activities. [4-5]. Laparoscopic colorectal surgery for cancer had an famed corner in recent surgery that besieged open approach, but laparoscopic approach may not be assumed in some regions due to cost or due to absent of qualified laparoscopic colorectal surgeons. [6]. Colorectal surgery has many troubles. The most troubled complication is anastomotic leakage. The prevalence of 
anastomotic leakage following colorectal resection and anastomosis may wave to $15 \%$ of cases with high morbidity and mortality [7-9].The inauguration of the stapler in colorectal surgery assisted the anastomosis to be in a homogeneous design, decrease strain on the suture, speedy surgery, no intraabdominal contamination, no intrusion of anastomotic site perfusion and narrow the prevalence of anastomotic leakage. [10-12]. Resection of rectum is linked to low anterior resection syndrome (LARS) that usually affects quality of life [13-14].

\section{Aim Of The Work, Gap Statement And Strength Of The Study:}

During colorectal cancer surgery, no conclusive path of resection and anastomosis and usually followed by the surgeons according to their experience. In the current study, we have organized a randomized clinical trial to analyze the outcomes in two groups of patients with colon and rectum cancers with two different open approaches for resection and anastomosis using single circular stapler. The primary aim was to correlate the prevalence of anastomotic leak after both interventions. The secondary aim was to appraise functional outcome and quality of life between both groups. The tertiary aim was to evaluate the morbidity and mortality rate during and after both techniques.

\section{Patients \& Methods}

3.1 Study design: This is a prospective randomized controlled trial managed in the colorectal surgical unit of our University Hospital (mono-center) between September 2016 to September 2018. A total of 74 patients diagnosed as cancer sigmoid and cancer rectum underwent colorectal cancer surgery. The patients were randomly labeled into two groups: Group (A): included 37 patients: Antegrade transabdominal open side to end colorectal anastomosis using single circular stapler and Group (B): included 37 patients: retrograde trans-anal open colorectal anastomosis using single circular stapler. As percentage of leakage from previous paper [39] was $29 \%$ VS $5.4 \%$ so sample will be 37 in each group with power $80 \%$ and confidence level $95 \%$ would be suitable to reach statistical significance $(p<0.05)$. It is a simple random sample with a balance. Patients were randomly allocated using a random sequence computer. Patients were randomly numbered in closed envelopes, which were opened just before accomplishing the anastomosis intraoperative. Patients were unaware to the any group until after the study. It is the role of registration office.

3.2 Participant criteria: patients had to complete the following aspects to be in the study: Sigmoid and rectum adenocarcinoma confirmed by biopsy and histo-pathological examination, expected R0 resection with immediate restoration of colorectal continuity with or without covering proximal ileostomy, patients $>18$ years, both sex, with or without neo-adjuvant treatment, residual rectal stump $>3 \mathrm{~cm}$ from anal verge for carcinoma rectum and clinically normal function of anal sphincter. Omission criteria included patients younger than 18 years, psychopathic patients, recurrent or non resectable cancer, combination operation, complicated cancer e.g. obstructed or perforated, tumor infiltrating anal sphincter and previous left sided colorectal surgery or ano-rectal surgeries. 


\subsection{Types of outcome and measurement (study endpoints):}

Primary outcome is the incidence of the anastomotic leak during hospital admission and during 30 days postoperative. Secondary outcomes are intestinal function and quality of life one month, six months, twelve months and 24 months postoperatively. Tertiary outcomes are the long and short term postoperative morbidities and mortality (within 90 days postoperative): including timing of surgery (in minutes), intraoperative hemorrhage $(\mathrm{ml})$, vessels disgrace at operation, Hematoma/Seroma, span of hospital admission (in days), wound infection at any time point, in-hospital mortality, ICU/days (intensive care unit admission) and stricture.

\subsection{Definitions and measurement of outcomes:}

The International Study Group of Rectal Cancer (ISREC) depicted anastomotic leak and labeled an ordered system for dealing with anastomotic leak following colorectal surgery into Grade A, Grade B and Grade C [15]. Intestinal function is reviewed by the Low Anterior Resection Syndrome (LARS) questionnaire, which comprises five queries (gas incontinence, incontinence of liquid stool, frequency of bowel movements, clustering of stools and urgency). Quality of life ( $Q \mathrm{oL})$ is estimated by Functional Assessment of Cancer Therapy-Colorectal (FACT-C). The FACT-C consists of: physical well-being (PWB), social well-being (SWB), emotional well-being (EWB), and functional well-being (FWB), and colorectal cancer symptoms (CCS) [16]. Postoperative morbidity is determined by Clavien and Dindo [17]. Anterior resection is assorted in congruity with colonoscopy measurement of tumor site from anal verge, 'high' $(>10 \mathrm{~cm})$, 'low' (>5 - $10 \mathrm{~cm})$, and 'ultralow' (within $3-5 \mathrm{~cm}$ ) [18].

\subsection{Method:}

Preoperative preparation included cancer staging including total colo-proctoscopy with tumor biopsy, CT and MRI of the abdomen, pelvis and chest. Neo-adjuvant chemo-radiotherapy is the role in our center in rectal cancers. Preparation of bowel (oral laxatives). With start of anesthesia, metronidazole $500 \mathrm{mg}$ and ceftriaxone 1gm. given intravenously. Prophylaxis against deep venous thrombosis with low molecular weight heparin $4000 \mathrm{UI}$.

General anesthesia using cuffed endotracheal intubation. All surgeries were performed in mono-center in colorectal surgery unit for duration of 24 months. At least one of three senior surgeons attended to ensure inclusion criteria. When resection of cancer was accustomed to be macroscopic margin free, randomization occurred. The patient was situated in the Lloyd-Davies position. Low midline incision was performed. Splenic flexure mobilization is standard in our center protocol except in dolico-colon cases. In cancer rectum, the rectum was released with meso-rectal excision and a clamp was adjusted to the rectum distal to the tumor with not less than $2 \mathrm{~cm}$ length and the rectum is divided. It was crucial to put nerve supply to urinary bladder and genital organ riskles. The opened stump of rectum was wiped with povidone iodine and the clamp was re-placed. In cancer sigmoid: removal of the sigmoid colon with at least $10 \mathrm{~cm}$ safety margin superior to the tumor and lower border was the rectum. In antegrade approach, the anvil was passed inside the rectal stump and anchored in place by purse string stitches using 
polypropylene 3-0 (Figure 1). A nail was preceded through the end of opened colon and through the colonic wall 4-6 cm from the colonic opening stump (Figure 2). In retrograde approach, the anvil head was introduced in the proximal colon and the purse-string suture was tied using polyprolene 3-0. The shaft of the circular stapler was introduced through the anal canal after courteous anal dilatation.

In both techniques, the circular stapler was closed with great discreet not to neither bend the colon nor comprise viscera. The stapler had been tightened, fired, and then smoothly removed. (Figure 3). The colonic stump in the antegrade group was closed in two layers (absorbable Vicryl 3-0 suture inner layer and the outer layer by non-absorbable Silk 3-0 suture).

To assess anastomosis, continuous circular two doughnuts (Figure 4) and air-leakage testing is implemented where placement of a clamp on the proximal colon and the pelvic cavity was overflowed with physiological saline and air is injected through the anus by syringe. Covering ileostomy was done in middle and low rectal anastomosis as a rule. Covering ileostomy was performed in any other cases of suspicious anastomosis according to the intraoperative surgeon opinion and was closed 4-6 weeks later. Two drains were inserted, one intra-peritoneal and the other in the pelvis near the anastomotic line. Fluid was permitted as tolerated. Antibiotics were maintained for 5 days and anticoagulant extended until the patients were fully roving. A drain removed when contains less than 50 C.C for 3 days.

The follow up period ( 2 years) was one month, six month, twelve month and twenty-four month after returning home. After homecoming, patients were connected by mailing, telephone and at outpatient clinic. Means of follow up included full history and physical examination to distinguish remote drawbacks, Colonoscopy after 6 months to detect stricture at site of anastomosis and Quality of life and intestinal function assessment by the suitable assessment questionnaire. All patients were certified to complete LARS, and quality of life questionnaires. 3 cases did not fulfill the assessment at 6 months. The number of patients lost during follow up period was 3 cases died after the first month assessment and before the 6 month assessment (one in group $A$ and 2 in groups $B$ ).

\section{Statistical Analysis}

Data collected throughout history, basic clinical examination, laboratory investigations and outcome measures coded, entered and analyzed using Microsoft Excel software. Data were then imported into Statistical Package for the Social Sciences (SPSS version 20.0) (Statistical Package for the Social Sciences) software for analysis. According to the type of data qualitative represent as number and percentage, quantitative continues group represent by mean $\pm S D$, the following tests were used to test differences for significance; . Difference and association of qualitative variable by Chi square test (X2). Differences between quantitative independent groups by t test multiple by ANOVA or fredman, independent predictors by logistic regression. $P$ value was set at $<0.05$ for significant results $\&<0.001$ for high significant result

\section{Results}


No statistically significant differences between studied groups as regard demographic and preoperative variables. The mean age was $62.58 \pm 12.3$ years and $61.03 \pm 13.98$ years in group $A$ and group $B$ respectively. Most cases were male patients (38/74). The most common comorbidities included hypertension (17.5\% of patients in both groups) and diabetes mellitus (16.2\%). Most of tumor site located in upper rectum (69\%) followed by middle and lower rectum (20\%) and least number in sigmoid $(11 \%)$. Table (1).

No statistically significant difference founded between studied group as regard all items of intraoperative variables except at operative time and mean anastomotic time as Group (A) was highly statistically significantly shorter $(\mathrm{p}=0.00)$. On the basis of the surgical procedures, eight cases $(10.8 \%)$ high anterior resection ( 4 side to end and 4 end to end), forty-one low anterior resection ( 23 side-to-end and 28 end -toend) and 15 ultra-low resection (10 cases in group A and 5 in group $B)$ were performed $(p=0.34)$. The overall incidence of intraoperative diagnosed air leakage was $6.8 \%$ (5/74 patients). Air leakage after sideto-end anastomosis was $5.4 \%$, while after end to end anastomosis was $8.1 \%(P=0.64)$. The caliber of the endo-stapler most frequently used was $33 \mathrm{~mm}$ in 43 cases $(58 \%)(p=0.77)$. Table (2).

No statistically significant difference founded between studied groups as regard all items of postoperative variables. There were 2 cases of anastomotic line bleeding in group A (5.4\%) and one patient in group $B,(2.7 \%)$. There were four cases of stricture of the anastomosis in both groups (2.7\%\&8.1\%). Postsurgical complications were surgical site infection (5.4\%\&4\%), ileus $(2.7 \% \& 5.4 \%)$, adhesive intestinal obstruction (2.7\%\&5.4\%) and intra-abdominal abscess (13.5\%\&8.1\%). Anastomotic leakage occurred in 5 patients $(13.5 \%)$ in the antegrade group and 3 patients $(8.1 \%)$ in the retrograde group $(P=0.47)$. most cases were grade $C$ leakage $(10.8 \% \& 2.7 \%)$. Majority of both groups were in class III followed by class II \& I Table (3).

Univariate analysis of anastomotic leak showed that perioperative blood loss $(p=0.001)$, length of stay $(p=0.0019)$, re-operation $(p=0.01)$, inpatient death $(p=0.0003)$, infection $(p=0.00)$ and bleeding $(p=0.018)$ were significantly associated with leakage. Table (4) while Multivariate analysis of anastomotic leak revealed that infection (OR 4.62, 95\% $\mathrm{Cl} 1.54-7.96)$ is the only independent predictors for anastomotic leak Table (ㅁ)

Clinical LARS score results comparing Side-to-end and End-to-end anastomosis showed that There is statistically significant change as regard range of bowel frequency in end to end group only $(p=0.04)$ and there is statistically significant difference as regard incontinence for Flatus in side to end group only $(0.00)$. There is statistically significant change in both group regard Incontinence for liquid stools $(p=0.00)$ and Clustering of stool (0.00 and 0.043). Table (6).

Percentage of satisfied QoL scores and at different time-points showed that the quality of life in Antegrade group significantly drop at 6 months and return to baseline after that as regard PWB, FWB and CCS with no difference as regard SWB \& EWB while in retrograde group, the same change happened only as regard PWB \& FWB but SWB and CCS percentage didn't return to baseline. Table(7). 


\section{Discussion}

In the current study, we found difficulty in performing purse string on the anvil in group $A$ and around the shaft in group B especially in low rectal cancer. However, univariate analysis of anastomotic leak affirmed that age, sex and site of anastomosis were not associated with anastomotic leakage. Moreover, no statistically significant difference between both groups as regards anastomotic leakage.

Ricciardi et al., and Beard et al., elaborated the usefulness of air-leak testing in recognizing leakage after colorectal resection and anastomosis. They stated that this test may detect leak in 7.9\% $-25 \%$ [19-20]. in the current study, 5/74(6.7\%) cases of air leakage (2 in Group A, 3 in Group B) were detected intraoperatively using air leakage test that we found to be simple and rapid and we see that it is witted to use this test in all cases. 3 cases required re-anastomosis. Air leak in retrograde approach probably due to difficult introduction of the shaft of the stapler through the anal canal that caused mucosal and submucosal tears. However, no statistically significant difference between both groups as regards intraoperative air leakage.

Splenic injury results in higher morbidity and its injury is better avoided by proper exposure and avoids dragging on spleno-colic ligament. [21]. in our study, accidental injury to spleen ensued in 3 cases (3/74) (8.1\%)in both groups and only one case required splenectomy in Group B. although splenic injury is higher in retrograde approach than antegrade approach, yet it is not statistically significant. splenic injury is higher in retrograde approach most probably due to larger number of cases that underwent splenic flexure mobilization than in group A. Univariate analysis affirmed that perioperative blood loss is significantly associated with anastomotic leakage. We ascertain that 2 cases encountered splenic injury had developed anastomotic leakage. One patient in each group that developed postoperative anastomotic leakage suffered from splenic injury.

In our study, we found that fashioning the anastomosis in group $A$ is shorter than in Group $B(13 \pm 1.2$ min and $23.5 \pm 13.7$ respectively) and shorter operative time in group $A$ is shorter in group $B(150 \pm 13$ min and $184 \pm 10$ min respectively).Longer time over anastomotic time fashioning in group $B$ is due to maneuver in the anal region to introduce the stapler like anal dilatation and repeated introduction of the stapler in smooth curve.

Anastomotic leak in the previous studies varies from $1.8 \%$ up to $24 \%$ with high morbidity and mortality [22-25]. In the present study, the incidence and severity of anastomotic leakage were higher in antegrade approach than retrograde approach yet, it is statistically insignificant result. 8 cases (10.8\%) developed anastomotic leakage ( 5 cases in Group A and 3 cases in Group B).Four cases (4/5) of anastomotic leakage in Group A were grade $\mathrm{C}$ while one case was grade $\mathrm{C}$ in Group B.

Anastomotic leak are multifactorial including gender, the site of the tumor, body mass index, anastomotic technique, unsuitability of purse string suture, anastomotic site contamination and mucosal tears [26-34]. In the present we disagree with the previous studies as there is no significant difference between the studied groups as regard age, sex and site of anastomosis and univariate analysis did not show 
association between site of anastomosis and anastomotic leak. We also, found other risk factors for leakage not discussed before and they include perioperative blood loss, re-operation, wound infection and bleeding from anastomotic line.

Multiple studies stated that site of anastomosis stricture occurred in $8 \%$ of cases and was attributed to anastomotic site ischemia or anastomotic leakage [35-36]. In the present study, a frequency of stricture of the anastomosis was higher in retrograde approach than antegrade approach $(2.7 \%(1 / 37)$ and $8.1 \%$ $(3 / 37)$ ). All cases required 3 successive endoscopic dilatation with one month interval. No cases required surgical re-intervention and no cases of stricture complained of leakage. We attribute the causes of stricture due to ischemia at the site of anastomosis from an excessive dissection adjacent to the anastomosis with subsequent ischemia as well as performance of colorectal anastomosis with stapler 28.

Local recurrence was not found within this short 24 months follow-up period. But the previous literatures revealed 3.5\%-12\% local recurrence. [37-38].It actually may be a limitation of this study.

Martellucci declared that up to $80 \%$ of patients underwent colorectal surgery developed LARS [39].In the present study, There is statistically significant change as regard range of bowel frequency in end to end group only and there is statistically significant difference as regard incontinence for Flatus in side to end group only. There is statistically significant change in both group regard Incontinence for liquid stools and Clustering of stool.

A study confirmed the effect of cancer on quality of life of patients underwent colorectal surgery [40].in the present study, it is mesmerizing to find that the quality of life in Antegrade group significantly drop at 6 months and return to baseline after that as regard PWB, FWB and CCS with no difference as regard SWB \& EWB while in retrograde group, the same change happened only as regard PWB \& FWB but SWB and CCS percentage didn't return to baseline

Mortality: Death rate in this study was $2.7 \%$ in antegrade group and $5.4 \%$ in retrograde group. Two cases died due to grade $\mathrm{C}$ anastomotic leak, one in both group. The third case died of CNS complication. A similar study showed a mortality of $2.4 \%$ [35]

\section{Conclusions And Recommendation}

The mean anastomotic time and mean operative time is shorter in antegrade approach than retrograde approach. The intraoperative and postoperative variables showed no statistically significant difference between both groups. Perioperative blood loss, length of stay, re-operation, inpatient death, infection and bleeding were significantly associated with leakage. Infection is the only independent predictors for anastomotic leak. There is statistically significant change as regard range of bowel frequency in end to end group only and there is statistically significant difference as regard incontinence for Flatus in side to end group only. There is statistically significant change in both group regard Incontinence for liquid stools and Clustering of stool (0.00 and 0.043). Percentage of satisfied QoL scores and at different time- 
points showed that the quality of life in Antegrade group significantly drop at 6 months and return to baseline after that as regard PWB, FWB and CCS with no difference as regard SWB \& EWB while in retrograde group, the same change happened only as regard PWB \& FWB but SWB and CCS percentage didn't return to baseline. Antegrade approach may be used as a safe alternative to antegrade approach in colorectal anastomosis.

\section{Limitations}

Mono-center study Short period of follow up to evaluate recurrence and small sample size to detect leakage incidence.

\section{Abbreviations}

LARS: low anterior resection syndrome

Qol: quality of life.

PWB: physical well-being.

FWB: functional well-being.

SWB: social well-being.

EWB: emotional well-being.

CCS colorectal cancer symptoms positive

CT: computerized tomography.

MRI: magnetic resonance imaging.

\section{Declarations}

Contributions of the Authors:

All the authors shared important intellectual content in study design, data analysis, written and critical revision. The version they submitted shared in their final approval.

INTEREST CONFLICT: It is not declared.

Availability of data and material statement: will be available from the authors on reasonable demand.

The Registration Registered quality control review criteria for clinicaltrials.gov protocol:

NCT04694521.registered in 05/01/2021. 


\section{Ethics approval:}

Faculty of Medical Ethical Committee Zagazig University gave us all the ethical agreement.

The described work has been carried out for human experiments in accordance with the World Medical Association's Code of Ethics (Helsinki Declaration).

The work has been reported in line with consolidated standards of reporting trials (CONSORT) guidelines Consent for participation and publication: after the study was included, all involved persons gave their informed written consent for participation and publication.

Conflict of interest: no

funding conflict: 'Not applicable'

\section{References}

[1] Parkin DM, Bray F, Ferlay J, Pisani P (2005) Global cancer statistics, 2002. CA Cancer J Clin 55: 74108.

[2] FERIAY J, BRAY F, PISANI P, GLOBOCAN 2000, Cancer Incidence, Mortality and Prevalence Worldwide. In: IARC CancerBase No 5, (IARC Press, Lyon, 2001).

[3] Ferlay J, Autier P, Boniol M, Heanue M, Colombet M, et al. (2007) Estimates of the cancer incidence and mortality in Europe in 2006. Ann Oncol 18: 581-592.

[4] Chiappa A, Biffı R, Zbar AP, et al.: Results of treatment of distal rectal carcinoma since the introduction of total mesorectal excision: A single unit experience 1994-2003. Int J Colorectal Dis 2005;20:221-230

[5] Murphy J, Hammond TM, Knowles $\mathrm{CH}$, et al.: Does anastomotic technique influence anorectal function after sphincter-saving rectal cancer resection? A systematic review of evidence from randomized trials. J Am Coll Surg 2007;204:673-680

[6] P. J. Hewett, R. A. Allardyce, P. F. Bagshaw et al., "Shortterm outcomes of the australasian randomized clinical study comparing laparoscopic and conventional open surgical treatments for colon cancer: the ALCCaS trial," Annals of Surgery, vol. 248, no. 5, pp. 728-738, 2008

[7] Jung SH, Yu CS, Choi PW, Kim DD, Park IJ, Kim HC, et al. Risk factors and oncologic impact of anastomotic leakage after rectal cancer surgery. Dis Colon Rectum 2008;51:902-8.

[8] Ho YH: Techniques for restoring bowel continuity and function after rectal cancer surgery. World $\mathrm{J}$ Gastroenterol 2006;12:6252- 6260. 
[9] Yang L, Huang X, Zhou J (2014). Risk assessment on anastomotic leakage after rectal cancer surgery: an analysis of 753 patients. Asian Pac J Cancer Prev, 14, 4447-53

[10] Korolija D (2008). The current evidence on stapled versus handsewn anastomoses in the digestive tract. Minimally Invasive Therapy \& Allied Technologies, 17, 151-4

[11] Taflampas P, Christodoulakis M, Tsiftsis DD. Anastomotic leakage after low anterior resection for rectal cancer: facts, obscurity and fiction. Surg Today 2009; 39:183-8

[12] Redmond HP, Austin OM, Clery AP, et al. Safety of doublestapled anastomosis in low anterior resection. Br J Surg 1993; 80:924-927

[13] Bryant CL, Lunniss PJ, Knowles CH et al (2012) Anterior resection syndrome. Lancet Oncol 13(9):e403-e408

[14] Emmertsen KJ, Laurberg S (2012) Low anterior resection syndrome score: development and validation of a symptom-based scoring system for bowel dysfunction after low anterior resection for rectal cancer. Ann Surg 255(5):922-928

[15] den Dulk M, Noter SL, Hendriks ER, et al. Improved diagnosis and treatment of anastomotic leakage after colorectal surgery. Eur J SurgOncol 2009;35(4):420-426

[16] Ward WL, Hahn EA, Mo F, et al. Reliability and validity of the

Functional Assessment of Cancer Therapy-Colorectal (FACT-C) quality of life instrument. Qual Life Res. 1999;8:181-95

[17] Clavien PA, Barkun J, de Oliveira ML, Vauthey JN, Dindo D, Schulick RD, de SE, Pekolj J, Slankamenac K, Bassi C, Graf R, Vonlanthen R, Padbury R, Cameron JL, Makuuchi M: The Clavien-Dindo classification of surgical complications: five-year experience. Ann Surg 2009, 250:187-196

[18] Portier, G, Ghouti, L, Kirzin, S, Guimbaud, R, Rives, M \& Lazorthes, F 'Oncological outcome of ultra-low coloanal anastomosis with and without intersphincteric resection for low rectal adenocarcinoma', $\mathrm{Br} \mathrm{J}$ Surg, 2007, 94 (3):341-45

[19] Ricciardi R, Roberts PL, Marcello PW, Hall JF, Read TE, Schoetz DJ. Anastomotic leak testing after colorectal resection: what are the data? Arch Surg 2009;144(5):407-411, discussion 411-412

[20] Beard JD, Nicholson ML, Sayers RD, Lloyd D, Everson NW. Intraoperative air testing of colorectal anastomoses: a prospective, randomized trial. Br J Surg 1990;77(10):1095-1097

[21] Cassar K, Munro A: latrogenic splenic injury. J R Coll Surg Edinb 2002, 47:731-741.

[22] Nesbakken A, Nygaard K, Lunde OC. Outcome and late functional results after anastomotic leakage following mesorectal excision for rectal cancer. Br J Surg. 2001; 88:400-404 
[23] Bielecki K. "Colon anastomosis É a challenge for the surgeon, a risk for the patient", Advances in Medical Sciences 1992, 5,233-5 (Postpy Nauk Medycznych)

[24] Matthiessen P, Hallbook O, Rutegard J (2007). Defunctioning stoma reduces symptomatic anastmotic leakage after low anterior resection of rectum for cancer, a randomized multicenter trial. Ann Sur, 246, 207-12

[25] Kube R, Mroczkowski P, Granowski D, Benedix F, Sahm M, Schmidt U, Gastinger I and Lippert H: Anastomotic leakage after colon cancer surgery: A predictor of significant morbidity and hospital mortality, and diminished tumor-free survival. Eur J Surg Oncol 36: 120-124, 2010

[26] Mirnezami A,Mirnezami R, Chandrakumaran K, Sasapu K, Sagar P, Finan P. Increased local recurrence and reduced survival from colorectal cancer following anastomotic leak: systematic review and metaanalysis. Ann Surg 2011;253(5):890-899.

[27] Platell C, Barwood N, Dorfmann G, Makin G: The incidence of anastomotic leaks in patients undergoing colorectal surgery. Colorectal Dis 2007, 9:71-79.

[28] Karanjia ND, Corder AP, Beam P and Heald RJ: Leakage from stapled low anastomosis after total mesorectal excision for carcinoma of the rectum. Br J Surg 81: 1224-1226 (1994).

[29] Vallance A, Wexner S, Berho M, Cahill R, Coleman M, Haboubi N, et al. A collaborative review of the current concepts and challenges of anastomotic leaks in colorectal surgery. Colorectal Dis 2017;19(1):0112.

[30] Bell S, Kong JC, Wale R, Staples M, Oliva K, Wilkins S, et al. The effect of increasing body mass index on laparoscopic surgery for colon and rectal cancer. Colorectal Dis 2018;20(9):778-88. https://doi.org/10.1111/codi.14107.]

[31] 2015 European Society of Coloproctology Collaborating Group. The impact of stapling technique and surgeon specialism on anastomotic failure after right-sided colorectal resection: an international multicentre, prospective audit. Colorectal Dis 2018;20(11):1028e40. https://doi.org/10.1111/codi.14308

[32] Brisinda G, Vanella S, Cadeddu F, Civello IM, Brandara F, Nigro C, et al. End-to-end versus end-to-side stapled anastomoses after anterior resection for rectal cancer. J Surg Oncol 2009; 99:75-9.

[33] Marecik SJ, Chaudhry V, Pearl R, Park JJ, Prasad LM. Singlestapled double-pursestring anastomosis after anterior resection of the rectum. Am J Surg 2007; 193:395-9.

[34] Roumen RM, Rahusen FT, Wijnen MH, Croiset van Uchalen FA. "Dog-ear" formation after doublestapled low anterior resection as a risk factor for anastomotic disruption. Dis Colon Rectum 2000; 43:5225 
[35] Cochrane Database Systematic Review, 2007, 'Stapled versus hand-sewn methods for colorectal anastomosis surgery,' The Cochrane Collaboration: John Wily and Sons.

[36] Orsay CP, Bass EM, Firfer B, Ramakrishnan V and Abcarian H: Blood flow in colon anastomotic stricture formation. Dis Colon Rectum 38: 202-206, 1995

[37] Moore, JW, Chapius, PH \& Bokey, EL 'Morbidity and mortality after single and double-stapled colorectal anastomosis in patients with carcinoma of the rectum', Aust N Z J Surg, 1996; 66 (12) 820-3

[38] Brigand, C, Roh, S \& Meyer, C 'Colorectal stapled anastomosis: results after anterior resection of the rectum for cancer', Ann Chir, 2004; 129 (8): 427-32.

[39] Martellucci J. (2016) Low Anterior Resection Syndrome: A Treatment Algorithm. Diseases of the Colon and Rectum, 59(1):79-82

[40] CONROY T, BLEIBERG H, GLIMELIUS B, Eur J Cancer, 39 (2003) 287.

\section{Tables}

Due to technical limitations the Tables are available as a download in the Supplemental Files.

\section{Figures}

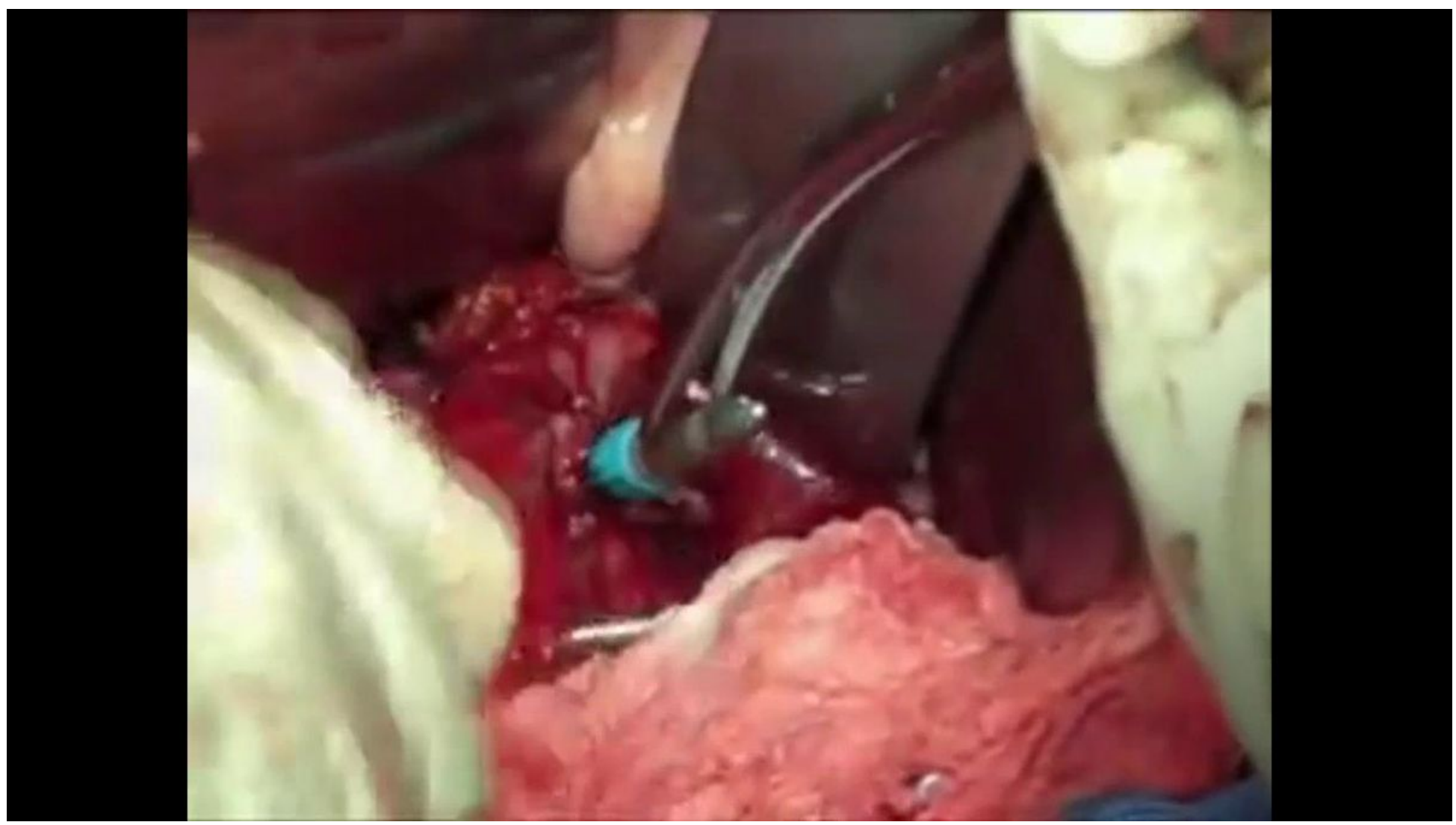


In antegrade approach,Anvil is introduced into the rectal stump and fixed by purse string using polyprolene 3-0 suture.

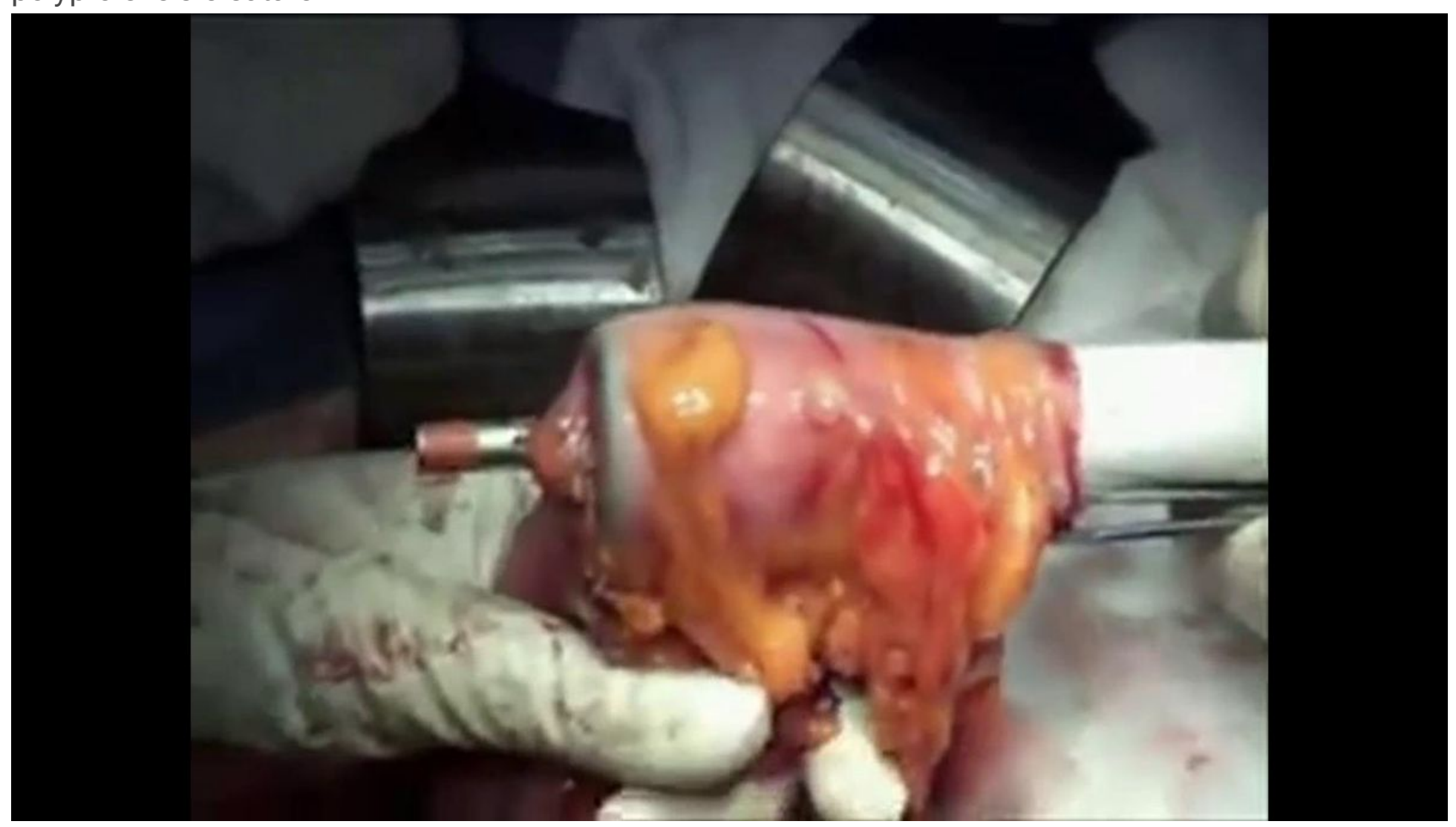

\section{Figure 2}

In antegrade approach, the shaft of circular stapler is inserted from the end of the colon and through the intestinal wall 4-6 $\mathrm{cm}$ from the stump. 


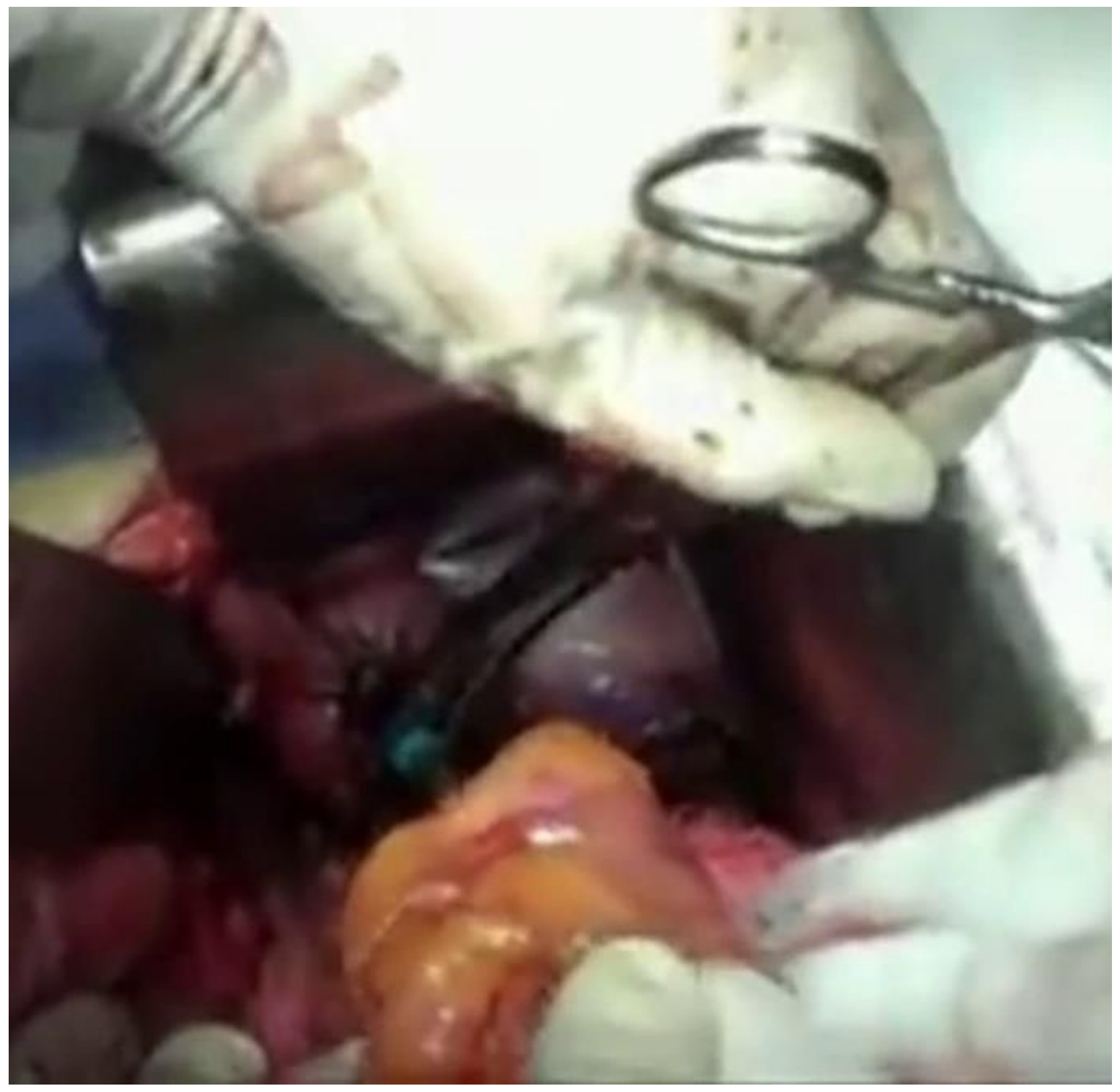

Figure 3

Both ends of the circular stapler are closed with care not to include any viscera. 


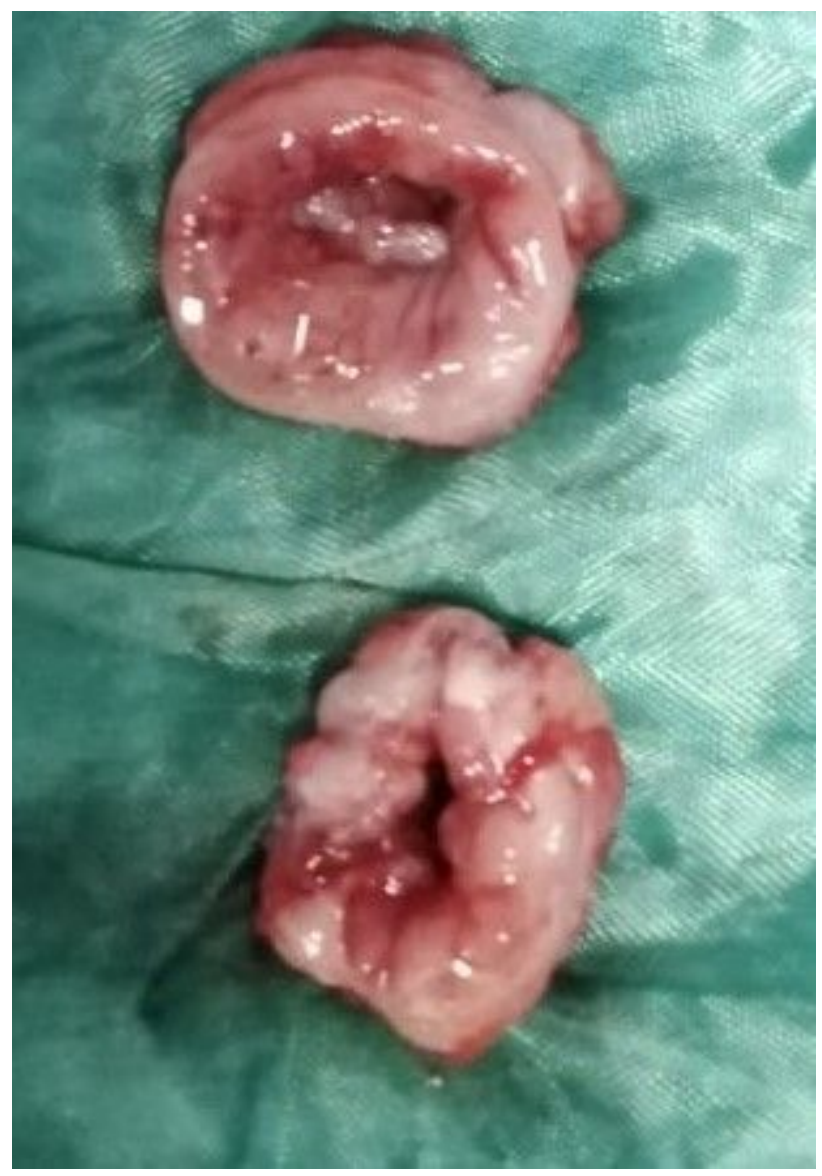

Figure 4

Doughnuts are inspected for completeness.

\section{Supplementary Files}

This is a list of supplementary files associated with this preprint. Click to download.

- tablesalltogether.pdf 